\title{
Medical Care Costs Associated With Cancer in Integrated Delivery Systems
}

\author{
Matthew P. Banegas, PhD ${ }^{\text {a }}$ K. Robin Yabroff, $\mathrm{PhD}^{\text {b}}$; Maureen C. O'Keeffe-Rosetti, MS \\ Debra P. Ritzwoller, $\mathrm{PhD}^{c}$; Paul A. Fishman, $\mathrm{PhD}^{\text {d; }}$ Ramzi G. Salloum, $\mathrm{PhD}^{\mathrm{e}}$; Jennifer Elston Lafata, $\mathrm{PhD}^{\mathrm{f}}$; \\ and Mark C. Hornbrook, $\mathrm{PhD}^{\mathrm{a}}$
}

\begin{abstract}
Background: The high economic burden of cancer is projected to continue growing. Cost-of-care estimates are key inputs for comparative effectiveness and economic analyses that aim to inform policies associated with cancer care. Existing estimates are based largely on SEERMedicare data in the elderly, leaving a knowledge gap regarding costs for patients aged $<65$ years. Methods: We estimated total and net medical care costs using data on individuals diagnosed with breast, colorectal, lung, or prostate cancer $(n=45,522)$ and noncancer controls $(n=314,887)$ enrolled in 1 of 4 participating health plans. Net costs were defined as the difference in mean total costs between patients with cancer and controls. The phase-of-care approach and Kaplan-Meier Sample Average method were used to estimate mean total and net 1 and 5-year costs (in 2015 US dollars) by cancer site, stage at diagnosis, and age group (<65 and $\geq 65$ years). Results: Total and net costs were consistently highest for lung cancer and lowest for prostate cancer. Net costs were higher across all cancer sites for patients aged $<65$ years than those aged $\geq 65$ years. Medical care costs for all cancers increased with advanced stage at diagnosis. Conclusions: This study improves understanding of medical care costs for the 4 most common invasive cancers in the United States. Higher costs among patients aged $<65$ years highlight limitations of relying on SEER-Medicare data alone to understand the national burden of cancer, whereas higher costs for patients with advanced-stage cancer underscore the importance of early detection to curtail high long-term costs. These cost estimates can be used in the development and evaluation of interventions and policies across the cancer care continuum.
\end{abstract}

J Natl Compr Canc Netw 2018;16(4):402-410 doi: 10.6004/jncen.2017.7065

\section{Background}

Cancer is the second most costly disease in the United States $^{1}$ and accounts for $5 \%$ to $11 \%$ of the annual total healthcare budget. ${ }^{2,3}$ Due to the rising prices and increased use of treatments, the costs of cancer care are increasing faster than the those for other diseases, ${ }^{4,5}$ with a projected growth of $27 \%$ between 2010 and 2020 based on increased prevalence alone. ${ }^{6}$ When increasing costs of treatment are considered, projected growth may be

aCenter for Health Research, Kaiser Permanente Northwest, Portland, Oregon; bDivision of Cancer Control and Population Sciences, Nationa Cancer Institute, Bethesda, Maryland; Institute for Health Research, Kaiser Permanente Colorado, Denver, Colorado; dDepartment of Health Services, University of Washington, Seattle, Washington; 'Department of Health Outcomes and Policy, College of Medicine, University of Florida, Gainesville, Florida; and fSchool of Pharmacy, University of North Carolina, Chapel Hill, North Carolina.

Submitted May 13, 2017; accepted for publication November 27, 2017. The authors have disclosed that they have no financial interests, arrangements, affiliations, or commercial interests with the manufacturers as high as $66 \%$ within this decade. ${ }^{6}$ Understanding the costs associated with cancer care across patient populations is critically important. As noted by Lipscomb, ${ }^{7}$ the importance of conceptually sound, empirically strong cancer care costs estimates are manifold, including (1) assessment of the aggregate economic burden of cancer at the national, state, or local level, (2) economic evaluation of interventions, such as through cost-effectiveness analysis, and (3) delineation of the cost of

of any products discussed in this article or their competitors. This work was supported by funding from the NCI (R01CA114204 and U24 CA171524). Parts of this work were presented at the 21st Annual HMO Research Network Conference; March 11-13, 2015; Long Beach, California. Author contributions: Study concept and design: Banegas, Yabroff, Hornbrook. Data analysis: Banegas, O'Keeffe-Rosetti. Interpretation of results: All authors. Manuscript preparation: All authors.

Correspondence: Matthew P. Banegas, PhD, Center for Health Research, Kaiser Permanente Northwest, 3800 North Interstate Ave, Portland, OR 97227-1110. Email: Matthew.P.Banegas@kpchr.org 
specific cancer interventions at the patient level to support informed decision-making.

Previous studies have used the nationally representative Medical Expenditure Panel Survey (MEPS) to estimate annual healthcare spending among cancer survivors in the United States. ${ }^{8-12}$ However, such studies based on household surveys include mainly longer-term cancer survivors and have a limited sample of individuals with poor-prognosis cancers, ${ }^{13}$ likely understating spending for this group. In addition, information on disease stage at diagnosis and date of death (where applicable) — factors known to be associated with medical care costs-are not available in the MEPS. All of these factors are important components for estimates used in modeling the costeffectiveness of cancer control programs and interventions, including those for prevention, early detection, treatment, and end-of-life (EOL) care.

Cancer registry-based estimates of cancer costs have relied primarily on the linked SEER-Medicare claims data and are usually limited to the costs of beneficiaries aged $\geq 65$ years. ${ }^{6,14-22}$ Cancer treatment has been reported to be more aggressive in younger patients aged $<65$ years, ${ }^{23-25}$ who represent nearly half of all new diagnoses. ${ }^{26}$ Earlier registry-based studies of the cost of cancer care in integrated health systems found that, when compared with similar individuals without a cancer history, net costs in the population diagnosed at age $<65$ years were higher compared with costs among the elderly. ${ }^{27}$ However these studies were based on data from the early 1990s, and treatment patterns have since changed substantially.

In this study, we used recent data to estimate the medical care costs of the 4 most commonly diagnosed invasive cancers in the United Statesbreast, colorectal (CRC), lung, and prostate cancers-among individuals aged $<65$ and $\geq 65$ years enrolled in 4 health plans affiliated with large, integrated health systems. The purpose of this study was to address a significant knowledge gap ${ }^{7}$ by expanding the empirical base of medical care cost estimates for patients diagnosed with cancer at age $\geq 18$ years in the United States, using a validated costing framework. ${ }^{14-16}$ Such cost estimates are important inputs for economic analyses, comparative effectiveness studies, and tools such as the NCI's Cancer Intervention and Surveillance Modeling Network (CISNET) that aim to guide public health research and priorities, and which can aid in the development of optimal cancer control strategies.

\section{Methods}

\section{Research Setting}

This study was conducted within 4 health plans that are members of the Cancer Research Network $(\mathrm{CRN})^{28,29}$ : Group Health Cooperative (Seattle, WA), Henry Ford Health System (Detroit, MI), Kaiser Permanente Colorado (Denver, CO), and Kaiser Permanente Northwest (Portland, OR). Each organization has a tumor registry and an integrated electronic health record (EHR) database. These plans provide both private and public health insurance coverage, including Medicare Advantage and Medicaid risk contracts. The Institutional Review Boards of the participating organizations approved all aspects of the project. The research setting, study design, and study population are described in more detail elsewhere. .0,31 $^{30}$

\section{Study Population}

The study population consisted of adults aged $\geq 18$ years diagnosed with de novo (tumor sequence 00 or 01) breast, CRC, lung, or prostate cancer $(n=45,522)$, and frequency-matched controls without a cancer history $(5: 1$ ratio to patients with cancer by 5 -year age group, sex, and health plan eligibility; $n=314,887$ ) who were enrolled in one of the participating health plans. Eligible patients were those diagnosed between January 1, 1988, and December 31, 2007, and who had at least 30 days of continuous health plan eligibility during the study period (January 1, 2000, through December 31, 2008). Controls were assigned a pseudo-diagnosis date based on their matched patient with cancer and had at least 30 days of continuous health plan eligibility during the study period. All participants were followed until date of death, disenrollment from health plan, or end of the observation (December 31, 2008).

\section{Data}

Data on patients with cancer were extracted from the accredited tumor registries of each participating health plan, including age at diagnosis, AJCC stage at diagnosis, calendar year of diagnosis, and tumor site. Race/ethnicity, sex, and vital status were extracted from health plan enrollment files, as were 
Banegas et al

cause of death and month and year of death for patients with cancer and controls who died within the study period. The Charlson-Deyo comorbidity index and health plan eligibility data were extracted from diagnosis and enrollment files, respectively.

Utilization data were extracted for all patients with cancer and controls between January 1, 2000, and December 31, 2008, from electronic data warehouses maintained by the health plans. The data warehouses compile information from EHRs; hospital discharge abstracts; claims; hospital, emergency room, same-day surgical, and medical office ambulatory care encounters; and outpatient dispensings. All participants, including Medicare Advantage enrollees, had coverage for ambulatory prescription medications. Data were standardized across the participating health plans according to specifications established by the CRN's Virtual Data Warehouse (VDW). ${ }^{32}$

\section{Phase-of-Care Approach}

The phase-of-care approach ${ }^{6,14-17}$ was used to assign medical care costs to distinct, clinically relevant phases on the basis of date of service in relation to cancer diagnosis and death: initial phase (first 12 months following diagnosis); EOL phase (final 12 months of life); and continuing phase (all months between the initial and EOL phases). ${ }^{16}$ Phases of care were defined based on previous studies of direct medical care costs. ${ }^{14,15,27,33}$ To further distinguish costs associated with cancer care during EOL, patients with cancer were stratified by cause of death (ie, cancer vs all other). Cost estimates were based on all medical care received by patients during the periods for which they were enrolled in the health plan over the study observation period; accordingly, not all patients contributed to all phases of care. ${ }^{34}$ Among patients who survived $<30$ months, application of the phase-of-care approach allocates the utilization and costs of care to the EOL phase first (12 months), followed by the initial phase (12 months), then the continuing phase ( $\leq 5$ months). ${ }^{16,17}$ For example, a patient with breast cancer who died 17 months after diagnosis would contribute the final 12 months to the EOL phase and the first 5 months to the initial phase, with no contribution to the continuing phase. In this study, patients diagnosed before January 1, 1999 (1 year prior the start of the study period), and who died in 2006 contributed months and costs of care to the continuing phase and the EOL phases only, because the utilization and costs of care for their initial phase were outside of the study observation period (see supplemental eFigure 1, available with this article at JNCCN.org).

Because control patients did not have a date of cancer diagnosis, they were assigned a pseudo-diagnosis date that corresponded to the date of diagnosis for their matched patient with cancer. Months of observation and costs of care were assigned to phases of care in the same manner used with patients with cancer.

The use of a control patient creates a counterfactual cohort of individuals without the disease of interest (ie, cancer) so as to estimate the incremental cancer-specific costs of medical care. This casecontrol approach for estimating cancer-specific costs is commonly accepted as a method for estimating the difference in costs of providing medical care for a patient with cancer versus providing medical care for a similar patient who does not have cancer. ${ }^{34}$

\section{Cost Estimates}

Medical care costs were estimated using the standardized relative resource cost algorithm (SRRCA). ${ }^{31}$ The SRRCA transforms encounter-level utilization data into nominal cost estimates that are consistent with, and generalizable to, 15 payment systems used by the Centers for Medicare \& Medicaid Services (CMS) to reimburse providers for covered services. The SRRCA adapts these payment systems into 12 different costing modules from the VDW utilization data associated with each of the following medical care categories: inpatient stays/days, same-day surgical procedures, outpatient visits, hospital ambulatory, pharmacy, hospice, home healthcare, skilled nursing facility, durable medical equipment, dialysis, telephone and email encounters, and other institutional services. Total monthly medical care costs were defined as the sum of standardized costs for all medical care categories. Mean total monthly estimates of cost of care were calculated for each cancer site (and controls) and each phase of care.

The mean net monthly cost (medical care costs associated with the cancer diagnosis), by phase of care, was defined as the difference in mean total monthly costs of care for patients with cancer versus control patients. Costs were reported in 2015 dollars, adjusted for inflation using the Consumer Price 
Index for Medical Care (base year of 2008), and discounted at 3\% annually.

\section{Statistical Analysis}

The Kaplan-Meier Sample Average (KMSA) method $^{19}$ was used to generate cost estimates by combining cancer site-specific and phase-specific mean monthly costs with monthly survival probability estimates from SEER cancer cases diagnosed from 1988 through 2008 (SEER 9) ${ }^{35}$ (see supplemental eFigure 2). Mean total and net long-term costs were calculated as described by Yabroff et al, ${ }^{36}$ with net costs defined as the difference in mean total costs between patients and controls. Mean total and net 1 - and 5-year costs were estimated, stratified by cancer site, stage, and age group ( $<65$ and $\geq 65$ years). We chose the durations of 1 and 5 years for cost estimates to reflect recent survival patterns and to make estimates comparable across the 18 tumor sites evaluated separately in this analysis. We used the age threshold of 65 years to create analytic subgroups because of the significance for Medicare age-eligibility, as well as to enable comparisons of our cost estimates with analyses that use the SEER-Medicare database. We did not break the $<65$ age group into substrata due to sample size and power limitations. A plausible range for cost estimates was calculated based on the upper and lower 95\% CI for phase-specific costs (see supplemental eTable 1), as previously described. ${ }^{36}$

\section{Results}

\section{Sample Characteristics}

Patients with breast cancer represented the largest group $(n=17,230)$, followed by prostate $(n=13,584)$, CRC $(n=7,895)$, and lung cancers $(n=6,813)$. As shown in Table 1, most patients with CRC (59.0\%), lung $(64.0 \%)$, and prostate $(57.7 \%)$ cancer were aged $\geq 65$ years at diagnosis, compared with only $35.9 \%$ of patients with breast cancer. Across all cancers, nonHispanic whites were the largest racial/ethnic group. Patients diagnosed with stage I or II cancers constituted most breast (91\%), CRC (62\%), and prostate (83\%) groups, whereas $68 \%$ of patients with lung cancer were diagnosed with stage III or IV disease. Median survival time was largest for patients with prostate cancer (199.9 months), followed by those with breast (177.9 months), CRC (79.8 months), and lung cancer (18.5 months).

\section{Costs by Cancer Site and Stage at Diagnosis}

Mean total and net monthly costs are presented by cancer site, stage, age group, and phase of care in Table 2. Across the 4 cancer sites, total and net costs were highest in the initial and EOL phases. Medical care costs were generally highest for lung cancer and lowest for prostate cancer.

Mean total 1-year costs for lung cancer ranged from $\$ 50,700$ (stage I) to $\$ 97,400$ (stage IV) among patients aged $<65$ years and from $\$ 44,000$ (stage I) to $\$ 71,200$ (stage IV) among patients aged $\geq 65$ years (Table 3 ). Mean total and net 1 -year costs for CRC were highest, across cancers, among patients aged $\geq 65$ years with stage IV disease $(\$ 74,500$ and $\$ 65,500$, respectively). Mean total 1-year costs for breast cancer were higher than those for CRC and prostate cancer among patients aged $<65$ years with stages II-IV disease (ranging from $\$ 53,100$ to $\$ 92,500$ ). Prostate cancer had the lowest costs in all stages among both age groups. Mean total 5-year costs followed the same pattern, with highest costs for lung cancer in stages I-III and for CRC in stage $\mathrm{IV}$, and lowest costs for prostate cancer.

\section{Costs by Age Group}

Within each cancer site and stage, medical care costs were generally higher among patients aged $<65$ than those aged $\geq 65$ (Table 3 ). For breast and lung cancers, patients aged $<65$ years had higher mean total and net costs than those aged $\geq 65$ years, across all stages; these differences in costs were greatest in stage IV. In breast cancer, for example, mean total 5-year costs for patients aged $<65$ years were $\$ 198,400$ versus $\$ 116,800$ for those aged $\geq 65$ years, and mean net 5 -year costs for patients aged $<65$ years were $\$ 172,900$ versus $\$ 77,100$ for those aged $\geq 65$ years. For CRC and prostate cancer, differences in mean total costs between age groups varied by stage at diagnosis; however, across all stages, mean net costs for patients aged $<65$ years were at least $\$ 1,400$ higher than costs for patients aged $\geq 65$ years.

\section{Total and Net Costs}

Comparing the mean total and net cost estimates, within cancer sites and stages, we observed the greatest differences among patients aged $\geq 65$ years, reflecting higher medical care costs in individuals without a cancer history in the older age group (Table 3). For example, the absolute differences between mean 
Banegas et al

\begin{tabular}{|c|c|c|c|c|c|c|c|c|}
\hline & \multicolumn{2}{|c|}{ Breast (Female $\left.{ }^{a}\right)$} & \multicolumn{2}{|c|}{ Colorectal } & \multicolumn{2}{|c|}{ Lung } & \multicolumn{2}{|c|}{ Prostate } \\
\hline & $\begin{array}{c}\text { Case } \\
n(\%) \\
(\mathrm{N}=17,230)\end{array}$ & $\begin{array}{c}\text { Control } \\
n(\%) \\
(\mathrm{N}=123,013)\end{array}$ & $\begin{array}{c}\text { Case } \\
n(\%) \\
(\mathrm{N}=7,895)\end{array}$ & $\begin{array}{c}\text { Control } \\
n(\%) \\
(N=53,945)\end{array}$ & $\begin{array}{c}\text { Case } \\
n(\%) \\
(\mathrm{N}=6,813)\end{array}$ & $\begin{array}{c}\text { Control } \\
n(\%) \\
(N=50,439)\end{array}$ & $\begin{array}{c}\text { Case } \\
n(\%) \\
(\mathrm{N}=13,584)\end{array}$ & $\begin{array}{c}\text { Control } \\
n(\%) \\
(\mathrm{N}=87,490)\end{array}$ \\
\hline \multicolumn{9}{|c|}{ Mean age at diagnosis/index, $y$} \\
\hline$<65$ & $11,039(64.1)$ & $77,284(62.8)$ & $3,239(41.0)$ & $20,703(38.4)$ & $2,456(36.1)$ & $16,105(31.9)$ & $5,753(42.4)$ & $34,879(39.9)$ \\
\hline$\geq 65$ & $6,191(35.9)$ & $45,729(37.2)$ & $4,656(59.0)$ & $33,242(61.6)$ & $4,357(64.0)$ & $34,334(68.1)$ & $7,831(57.7)$ & $52,611(60.1)$ \\
\hline \multicolumn{9}{|l|}{ Sex } \\
\hline Female & $17,230(100)$ & $123,013(100)$ & $3,889(49.3)$ & $26,977(50.0)$ & $3,328(48.9)$ & $25,085(49.7)$ & NA & NA \\
\hline Male & NA & NA & $4,006(50.7)$ & $26,968(50.0)$ & $3,485(51.2)$ & $25,354(50.3)$ & $13,584(100)$ & $87,490(100)$ \\
\hline \multicolumn{9}{|l|}{ Race } \\
\hline Asian, $\mathrm{NH}$ & $547(3.2)$ & $3,069(2.5)$ & $249(3.2)$ & $783(1.5)$ & $160(2.4)$ & $843(1.7)^{b}$ & $230(1.7)$ & $945(1.1)^{b}$ \\
\hline Black, NH & $1,082(6.3)$ & $7,353(6.0)$ & $555(7.0)$ & $2,593(4.8)$ & $530(7.8)$ & $3,066(6.1)$ & $1,698(12.5)$ & $4,720(5.4)$ \\
\hline Hispanic & $740(4.3)$ & $3,142(2.6)$ & $250(3.2)$ & $1,089(2.0)$ & $123(1.8)$ & $985(2.0)$ & $266(2.0)$ & $1,247(1.4)$ \\
\hline White, $\mathrm{NH}$ & $14,287(82.9)$ & $66,998(54.5)$ & $6,421(81.3)$ & $28,836(53.5)$ & $5,578(81.9)$ & $27,887(55.3)$ & $10,853(79.9)$ & $40,788(46.6)$ \\
\hline Other/Unknown & $574(3.3)$ & $42,451(34.5)$ & $420(5.3)$ & $20,644(38.3)$ & $422(6.2)$ & $17,658(35.0)$ & $537(4.0)$ & $39,790(45.5)$ \\
\hline \multicolumn{9}{|l|}{ Year of diagnosis } \\
\hline$\leq 1995$ & $3,667(21.3)$ & $26,564(21.6)$ & $1,373(17.4)$ & $10,196(18.9)$ & $377(5.5)$ & $2,780(5.5)$ & $1,975(14.5)$ & $17,916(20.5)^{b}$ \\
\hline 1996-1999 & $3,826(22.2)$ & $26,219(21.3)$ & $1,432(18.1)$ & $9,421(17.5)$ & $793(11.6)$ & $5,787(11.5)$ & $3,356(24.7)$ & $18,688(21.4)$ \\
\hline 2000-2005 & $6,544(37.9)$ & $45,557(37.0)$ & $3,378(42.8)$ & $22,485(41.7)$ & $3,746(55.0)$ & $27,570(54.7)$ & $5,360(39.5)$ & $32,812(37.5)$ \\
\hline $2006-2008$ & $3,193(18.5)$ & $24,673(20.1)$ & $1,712(21.7)$ & $11,843(22.0)$ & $1,897(27.8)$ & $14,302(28.4)$ & $2,893(21.3)$ & $18,074(20.7)$ \\
\hline \multicolumn{9}{|c|}{ Charlson comorbidity index score } \\
\hline 0 & $11,541(67.0)$ & $86,371(70.2)$ & $4,290(54.3)$ & $32,709(60.6)$ & $2,177(32.0)$ & $29,915(59.3)^{\mathrm{b}}$ & $8,022(59.1)$ & $51,009(58.3)^{b}$ \\
\hline 1 & $3,529(20.5)$ & $21,990(17.9)$ & $1,724(21.8)$ & $11,108(20.6)$ & $2,304(33.8)$ & $10,466(20.8)$ & $3,057(22.5)$ & $18,614(21.3)$ \\
\hline$\geq 2$ & $2,160(12.5)$ & $14,652(11.9)$ & $1,881(23.8)$ & $10,128(18.8)$ & 2,332 (34.2) & 10,058 (19.9) & $2,505(18.4)$ & $17,867(20.4)$ \\
\hline \multicolumn{9}{|l|}{ Stage at diagnosis } \\
\hline 1 & $9,525(55.3)$ & NA & 2,352 (29.8) & NA & $1,758(25.8)$ & NA & $576(4.2)$ & NA \\
\hline II & $6,060(35.2)$ & & $2,503(31.7)$ & & $416(6.1)$ & & $10,717(78.9)$ & \\
\hline III & $1,268(7.4)$ & & $1,985(25.1)$ & & $1,886(27.7)$ & & $1,369(10.1)$ & \\
\hline IV & $377(2.2)$ & & $1,055(13.4)$ & & $2,753(40.4)$ & & $922(6.8)$ & \\
\hline \multicolumn{9}{|c|}{ Mean/Median survival, mo } \\
\hline & 200.1/177.9 & $225.3 / 211.8$ & $130.3 / 79.8$ & 199.2/171.8 & $46.3 / 18.5$ & $126.3 / 98.8$ & 206.1/199.9 & 220.4/211.75 \\
\hline
\end{tabular}

Abbreviations: $\mathrm{NA}$, not applicable; $\mathrm{NH}$, non-Hispanic

a Male patients with breast cancer were excluded from the analysis due to very low prevalence.

bStatistically significant difference between cases and controls at $P \leq .05$.

total and net 1 -year cost estimates among patients with stage I disease aged $\geq 65$ years were approximately $\$ 8,100$ (breast cancer), $\$ 8,900$ (CRC), $\$ 8,600$ (lung cancer), and $\$ 8,500$ (prostate cancer), whereas among those aged $<65$ years, these differences were approximately $\$ 4,700, \$ 4,900, \$ 5,200$, and $\$ 5,100$, respectively.

\section{Discussion}

This study provides valuable information on the total and net direct costs of medical care for the 4 most commonly diagnosed cancers in the United States among patients diagnosed at ages $<65$ and $\geq 65$ years. Our study extends prior studies based on SEER-Medicare fee-for-service claims data ${ }^{14-19,37,38}$ by providing costs-of-care estimates for patients with cancer aged $\geq 65$ years who receive their Medicare benefits through private health plans (ie, Medicare Advantage), ${ }^{27,39}$ which accounted for $31 \%$ of Medicare enrollees in 2016. Consistent with earlier studies, our findings show high costs of medical care for patients with CRC and lung cancer, and higher costs among patients diagnosed with advanced versus earlier-stage disease in the fee-for-service setting. ${ }^{15,33}$

Findings from this study address a significant knowledge gap by updating registry-based estimates of medical care costs among US patients with can- 
Medical Care Costs of Cancer

\begin{tabular}{|c|c|c|c|c|c|c|c|c|}
\hline & \multicolumn{2}{|c|}{ Breast (Female) ${ }^{\mathrm{b}}$} & \multicolumn{2}{|c|}{ Colorectal } & \multicolumn{2}{|c|}{ Lung } & \multicolumn{2}{|c|}{ Prostate } \\
\hline & $\begin{array}{c}\text { Age }<65 \text { y } \\
(N=11,039)\end{array}$ & $\begin{array}{l}\text { Age } \geq 65 \text { y } \\
(\mathrm{N}=6,191)\end{array}$ & $\begin{array}{c}\text { Age }<65 \text { y } \\
(N=3,239)\end{array}$ & $\begin{array}{l}\text { Age } \geq 65 \text { y } \\
(\mathrm{N}=4,656)\end{array}$ & $\begin{array}{l}\text { Age }<65 \text { y } \\
(\mathrm{N}=2,456)\end{array}$ & $\begin{array}{l}\text { Age } \geq 65 \text { y } \\
(N=4,357)\end{array}$ & $\begin{array}{c}\text { Age }<65 \text { y } \\
(\mathrm{N}=5,753)\end{array}$ & $\begin{array}{l}\text { Age } \geq 65 \text { y } \\
(\mathrm{N}=7,831)\end{array}$ \\
\hline \multicolumn{9}{|l|}{ Stage I } \\
\hline \multicolumn{9}{|l|}{ Total } \\
\hline Initial & $\$ 2,902$ & $\$ 2,576$ & $\$ 2,924$ & $\$ 3,037$ & $\$ 4,343$ & $\$ 3,763$ & $\$ 1,538$ & $\$ 1,491$ \\
\hline \multicolumn{9}{|l|}{ End-of-life } \\
\hline Cancer death & $\$ 7,770$ & $\$ 3,544$ & $\$ 5,455$ & $\$ 3,528$ & $\$ 5,074$ & $\$ 4,338$ & $\$ 5,143$ & $\$ 2,862$ \\
\hline Other death & $\$ 5,414$ & $\$ 3,201$ & $\$ 4,594$ & $\$ 3,819$ & $\$ 5,121$ & $\$ 4,421$ & $\$ 9,809$ & $\$ 3,220$ \\
\hline \multicolumn{9}{|l|}{ Net } \\
\hline Initial & $\$ 2,494$ & $\$ 1,886$ & $\$ 2,509$ & $\$ 2,289$ & $\$ 3,912$ & $\$ 3,044$ & $\$ 1,099$ & $\$ 761$ \\
\hline Continuing & $\$ 243$ & $\$ 134$ & $\$ 308$ & $\$ 67$ & $\$ 594$ & $\$ 363$ & $\$ 282$ & $\$ 131$ \\
\hline \multicolumn{9}{|l|}{ End-of-life } \\
\hline Cancer death & $\$ 7,267$ & $\$ 2,774$ & $\$ 4,930$ & $\$ 2,734$ & $\$ 3,934$ & $\$ 3,169$ & $\$ 4,568$ & $\$ 2,066$ \\
\hline \multicolumn{9}{|l|}{ Stage II } \\
\hline \multicolumn{9}{|l|}{ Total } \\
\hline Initial & $\$ 4,560$ & $\$ 3,411$ & $\$ 4,036$ & $\$ 3,857$ & $\$ 5,839$ & $\$ 4,801$ & $\$ 1,821$ & $\$ 1,995$ \\
\hline Continuing & $\$ 921$ & $\$ 1,041$ & $\$ 842$ & $\$ 891$ & $\$ 1,496$ & $\$ 1,415$ & $\$ 688$ & $\$ 889$ \\
\hline \multicolumn{9}{|l|}{ End-of-life } \\
\hline Cancer death & $\$ 5,885$ & $\$ 3,463$ & $\$ 5,325$ & $\$ 4,063$ & $\$ 7,448$ & $\$ 4,696$ & $\$ 6,249$ & $\$ 4,105$ \\
\hline Other death & $\$ 5,396$ & $\$ 3,118$ & $\$ 5,703$ & $\$ 3,455$ & $\$ 6,539$ & $\$ 5,015$ & $\$ 5,101$ & $\$ 3,393$ \\
\hline \multicolumn{9}{|l|}{ Net } \\
\hline Initial & $\$ 4,152$ & $\$ 2,721$ & $\$ 3,622$ & $\$ 3,109$ & $\$ 5,407$ & $\$ 4,082$ & $\$ 1,383$ & $\$ 1,265$ \\
\hline Continuing & $\$ 418$ & $\$ 272$ & $\$ 317$ & $\$ 97$ & $\$ 949$ & $\$ 608$ & $\$ 113$ & $\$ 94$ \\
\hline \multicolumn{9}{|l|}{ End-of-life } \\
\hline Cancer death & $\$ 5,381$ & $\$ 2,694$ & $\$ 4,800$ & $\$ 3,270$ & $\$ 6,902$ & $\$ 3,889$ & $\$ 5,674$ & $\$ 3,310$ \\
\hline Other death & $\$ 1,274$ & $\$ 462$ & $\$ 1,636$ & $\$ 775$ & $\$ 2,471$ & $\$ 2,011$ & $\$ 1,558$ & $\$ 446$ \\
\hline \multicolumn{9}{|l|}{ Stage III } \\
\hline \multicolumn{9}{|l|}{ Total } \\
\hline Initial & $\$ 6,428$ & $\$ 4,645$ & $\$ 5,283$ & $\$ 4,868$ & $\$ 6,973$ & $\$ 5,869$ & $\$ 2,177$ & $\$ 2,335$ \\
\hline Cancer death & $\$ 7,211$ & $\$ 4,681$ & $\$ 6,495$ & $\$ 4,420$ & $\$ 7,698$ & $\$ 6,002$ & $\$ 4,829$ & $\$ 4,860$ \\
\hline Other death & $\$ 7,157$ & $\$ 3,304$ & $\$ 6,491$ & $\$ 4,408$ & $\$ 6,526$ & $\$ 5,699$ & $\$ 5,584$ & $\$ 3,224$ \\
\hline \multicolumn{9}{|l|}{ Net } \\
\hline Initial & $\$ 6,019$ & $\$ 3,954$ & $\$ 4,869$ & $\$ 4,120$ & $\$ 6,541$ & $\$ 5,150$ & $\$ 1,739$ & $\$ 1,605$ \\
\hline Continuing & $\$ 678$ & $\$ 404$ & $\$ 385$ & $\$ 237$ & $\$ 817$ & $\$ 703$ & $\$ 219$ & $\$ 206$ \\
\hline End-of-life & & & & & & & & \\
\hline Cancer death & $\$ 6,708$ & $\$ 3,911$ & $\$ 5,970$ & $\$ 3,626$ & $\$ 7,152$ & $\$ 5,196$ & $\$ 4,254$ & $\$ 4,065$ \\
\hline Other death & $\$ 3,035$ & $\$ 648$ & $\$ 2,423$ & $\$ 1,728$ & $\$ 2,458$ & $\$ 2,694$ & $\$ 2,041$ & $\$ 276$ \\
\hline Stage IV & & & & & & & & \\
\hline Total & & & & & & & & \\
\hline Initial & $\$ 7,980$ & $\$ 4,318$ & $\$ 7,303$ & $\$ 6,405$ & $\$ 8,201$ & $\$ 5,929$ & $\$ 2,326$ & $\$ 2,072$ \\
\hline Continuing & $\$ 2,719$ & $\$ 1,598$ & $\$ 2,978$ & $\$ 1,613$ & $\$ 2,424$ & $\$ 2,263$ & $\$ 1,117$ & $\$ 1,085$ \\
\hline End-of-life & & & & & & & & \\
\hline Cancer death & $\$ 6,602$ & $\$ 6,097$ & $\$ 7,609$ & $\$ 6,253$ & $\$ 9,743$ & $\$ 7,281$ & $\$ 5,988$ & $\$ 3,694$ \\
\hline Other death & $\$ 7,110$ & $\$ 5,399$ & $\$ 8,384$ & $\$ 6,798$ & $\$ 7,924$ & $\$ 6,286$ & $\$ 4,967$ & $\$ 3,671$ \\
\hline Net & & & & & & & & \\
\hline Initial & $\$ 7,572$ & $\$ 3,627$ & $\$ 6,889$ & $\$ 5,657$ & $\$ 7,770$ & $\$ 5,210$ & $\$ 1,887$ & $\$ 1,342$ \\
\hline Continuing & $\$ 2,215$ & $\$ 828$ & $\$ 2,453$ & $\$ 819$ & $\$ 1,878$ & $\$ 1,456$ & $\$ 542$ & $\$ 290$ \\
\hline End-of-life & & & & & & & & \\
\hline Cancer death & $\$ 6,099$ & $\$ 5,327$ & $\$ 7,084$ & $\$ 5,459$ & $\$ 9,196$ & $\$ 6,475$ & $\$ 5,413$ & $\$ 2,899$ \\
\hline Other death & $\$ 2,988$ & $\$ 2,742$ & $\$ 4,317$ & $\$ 4,119$ & $\$ 3,856$ & $\$ 3,281$ & $\$ 1,425$ & $\$ 724$ \\
\hline
\end{tabular}

aEstimates are mean total and net monthly costs of direct medical care by cancer site, stage at diagnosis, age at diagnosis, and phase of care. Costs were calculated using the Kaplan-Meier Sample Average estimators. ${ }^{19}$

bMale patients with breast cancer were excluded from the analysis due to very low prevalence.

cer aged $<65$ years, ${ }^{27}$ and extending studies based on cancer survivors in the MEPS ${ }^{10}$ by providing cost estimates that incorporate key clinical information, such as stage of disease, as well as timing of cancer diagnosis and survival, which enabled estimation of monthly phase-of-care costs (initial, continuing, and
EOL phases). Our results indicate that net costs of care were higher among patients aged $<65$ years versus those aged $\geq 65$ years across cancer sites and stages. Net costs of care were highest for patients aged $<65$ years with advanced-stage cancers, suggesting that early detection and prevention strategies are 
Banegas et al

\begin{tabular}{|c|c|c|c|c|c|c|c|c|c|c|c|c|c|c|c|c|}
\hline & \multicolumn{4}{|c|}{ Breast $^{b}$} & \multicolumn{4}{|c|}{ Colorectal } & \multicolumn{4}{|c|}{ Lung } & \multicolumn{4}{|c|}{ Prostate } \\
\hline & \multicolumn{2}{|c|}{$\begin{array}{c}\text { Age }<65 \text { y } \\
(\mathrm{N}=11,039)\end{array}$} & \multicolumn{2}{|c|}{$\begin{array}{l}\text { Age } \geq 65 \text { y } \\
(\mathrm{N}=6,191)\end{array}$} & \multicolumn{2}{|c|}{$\begin{array}{l}\text { Age }<65 \text { y } \\
(\mathrm{N}=3,239)\end{array}$} & \multicolumn{2}{|c|}{$\begin{array}{l}\text { Age } \geq 65 \text { y } \\
(\mathrm{N}=4,656)\end{array}$} & \multicolumn{2}{|c|}{$\begin{array}{l}\text { Age }<65 \text { y } \\
(\mathrm{N}=2,456)\end{array}$} & \multicolumn{2}{|c|}{$\begin{array}{l}\text { Age } \geq 65 \text { y } \\
(\mathrm{N}=4,357)\end{array}$} & \multicolumn{2}{|c|}{$\begin{array}{l}\text { Age }<65 \text { y } \\
(\mathrm{N}=5,753)\end{array}$} & \multicolumn{2}{|c|}{$\begin{array}{l}\text { Age } \geq 65 \text { y } \\
(\mathrm{N}=7,831)\end{array}$} \\
\hline & Total & Net & Total & Net & Total & Net & Total & Net & Total & Net & Total & Net & Total & Net & Total & Net \\
\hline \multicolumn{17}{|l|}{ Stage I } \\
\hline 1-year & $\$ 33.8$ & $\$ 29.1$ & $\$ 30.0$ & $\$ 21.9$ & $\$ 34.1$ & $\$ 29.2$ & $\$ 35.5$ & $\$ 26.6$ & $\$ 50.7$ & $\$ 45.5$ & $\$ 44.0$ & $\$ 35.4$ & $\$ 18.0$ & $\$ 12.9$ & $\$ 17.4$ & $\$ 8.9$ \\
\hline 5-year & $\$ 61.1$ & $\$ 36.0$ & $\$ 64.4$ & $\$ 25.2$ & $\$ 65.1$ & $\$ 38.9$ & $\$ 67.9$ & $\$ 26.8$ & $\$ 93.8$ & $\$ 66.2$ & $\$ 89.6$ & $\$ 48.1$ & $\$ 51.8$ & $\$ 23.3$ & $\$ 54.3$ & $\$ 13.4$ \\
\hline \multicolumn{17}{|l|}{ Stage II } \\
\hline 1-year & $\$ 53.1$ & $\$ 48.4$ & $\$ 39.7$ & $\$ 31.6$ & $\$ 47.1$ & $\$ 42.2$ & $\$ 44.9$ & $\$ 36.0$ & $\$ 68.3$ & $\$ 63.2$ & $\$ 55.9$ & $\$ 47.3$ & $\$ 21.2$ & $\$ 16.1$ & $\$ 23.3$ & $\$ 14.7$ \\
\hline 5-year & $\$ 85.9$ & $\$ 60.8$ & $\$ 79.0$ & $\$ 39.7$ & $\$ 77.5$ & $\$ 51.2$ & $\$ 77.8$ & $\$ 36.7$ & $\$ 126.5$ & $\$ 98.9$ & $\$ 111.4$ & $\$ 69.9$ & $\$ 47.5$ & $\$ 19.1$ & $\$ 58.0$ & $\$ 17.2$ \\
\hline \multicolumn{17}{|l|}{ Stage III } \\
\hline 1-year & $\$ 74.9$ & $\$ 70.1$ & $\$ 54.0$ & $\$ 45.9$ & $\$ 61.6$ & $\$ 56.8$ & $\$ 56.6$ & $\$ 47.8$ & $\$ 81.6$ & $\$ 76.3$ & $\$ 68.5$ & $\$ 59.7$ & $\$ 25.4$ & $\$ 20.3$ & $\$ 27.2$ & $\$ 18.7$ \\
\hline 5-year & $\$ 117.9$ & $\$ 92.6$ & $\$ 98.4$ & $\$ 58.8$ & $\$ 94.4$ & $\$ 68.2$ & $\$ 94.8$ & $\$ 53.8$ & $\$ 136.0$ & $\$ 108.2$ & $\$ 129.9$ & $\$ 88.1$ & $\$ 55.7$ & $\$ 27.2$ & $\$ 66.1$ & $\$ 25.3$ \\
\hline \multicolumn{17}{|l|}{ Stage IV } \\
\hline 1-year & $\$ 92.5$ & $\$ 87.5$ & $\$ 51.4$ & $\$ 43.0$ & $\$ 85.3$ & $\$ 80.2$ & $\$ 74.5$ & $\$ 65.5$ & $\$ 97.4$ & $\$ 91.8$ & $\$ 71.2$ & $\$ 62.3$ & $\$ 27.4$ & $\$ 22.2$ & $\$ 24.5$ & $\$ 15.8$ \\
\hline 5-year & $\$ 198.4$ & $\$ 172.9$ & $\$ 116.8$ & $\$ 77.1$ & $\$ 205.9$ & $\$ 179.3$ & $\$ 141.2$ & $\$ 99.9$ & $\$ 200.3$ & $\$ 172.0$ & $\$ 166.9$ & $\$ 124.9$ & $\$ 72.3$ & $\$ 43.7$ & $\$ 68.4$ & $\$ 27.3$ \\
\hline
\end{tabular}

${ }^{a}$ Estimates of total direct costs of medical care were calculated as total cost for cases, stratified by cancer site, stage, and age group. Estimates of net direct costs of medical care were calculated as total cost for cases minus total cost for controls, by each cancer site, stage, and age group. All estimates are presented in thousands (eg, $\$ 61.6=\$ 61,600$ ), rounded to nearest hundred, adjusted to 2015 US dollars using the Consumer Price Index for Medical Care (http://www.bls.gov/cpi/), base year 2008, and discounted at 3\% annually. One-year cost estimates are based on healthcare costs in the first year following cancer diagnosis, and 5 -year costs are based on healthcare costs in the 5 years immediately following cancer diagnosis. Total patient-months for breast controls (age $<65$ years $=3,775,790$ and $\geq 65$ years $=2,481,580$ ), colorectal controls (age $<65$ years $=1,030,877$ and $\geq 65$ years $=2,481,580$ ), prostate controls (age $<65$ years $=1,714,696$ and $\geq 65$ years $=2,652,419$ ), and lung controls (age $<65$ years $=756,834$ and $\geq 65$ years $=1,577,939$ ).

${ }^{b}$ Male patients with breast cancer were excluded from the analysis due to very low prevalence.

key to curtailing high long-term costs associated with late-stage disease. This also emphasizes the need for continued effective cancer screening, as outlined by the US Preventive Services Task Force, ${ }^{40-42}$ and for heeding the significance of the Healthy People 2020 objectives $^{43}$ to reduce the number of invasive $\mathrm{CRC}$ and late-stage female breast cancer diagnoses. Given the significant proportion of patients in the United States aged $<65$ years diagnosed with breast $(58 \%)$, colorectal $(42 \%)$, lung $(31 \%)$, or prostate cancer $(43 \%),{ }^{44}$ these trends further illustrate the limitations of relying on SEER-Medicare data alone to understand the costs of cancer care in the United States.

Importantly, the monthly phase-of-care, 1 -year, and 5-year cost estimates provided in our study, stratified by age at diagnosis, stage at diagnosis, and total versus net cost, serve as a unique resource that can be used in comparative effectiveness and economic analyses to inform the development and evaluation of interventions and policies associated with medical care across the cancer continuum..$^{45}$ Escalating cancer prevalence points to an increasing demand for cancer care services and underscores the utility of studies that examine the cost of cancer care in formulating future directions and research priorities. ${ }^{46} \mathrm{Ap}$ proximately half of all new cancer diagnoses (46\%) in the United States comprise breast, CRC, lung, or prostate cancer, and survival among individuals diagnosed with these cancers has increased significantly over the past decade ${ }^{47,48}$; accordingly, it is imperative that we understand the potential long-term cost implications for patients diagnosed with these common cancers. Additionally, several new valuebased payment models, such as the CMS Oncology Care Model and ASCO's Patient-Centered Oncology Payment model, all indicate a shift away from fee-for-service payments to bundled and episode-ofcare payments, which are hallmarks of integrated healthcare systems.

Although our study has many strengths, findings should be considered in light of certain limitations. First, study estimates reflect mean total and net costs of medical care for individuals enrolled in 4 participating integrated health plans and, thus, are most generalizable to patients diagnosed with cancer who receive care in similar delivery settings. Moreover, our study population was composed of predominately non-Hispanic white, insured patients; accordingly, the cost estimates presented in our study may underestimate cancer care costs in other US patient populations. Second, reported cost estimates reflect utilization patterns of populations enrolled in participating health plans from 2000 through 2008. As 
such, our estimates may be conservative, because they do not account for novel, high-cost cancer therapies and other medical care technologies introduced after 2008. As comprehensive data on the utilization of newer cancer therapies and technologies across different health settings become available, future studies that estimate the associated costs of medical care will be imperative. Nonetheless, to our knowledge, these results afford the most contemporary estimates of cancer-related costs among US patients aged $<65$ years receiving care in integrated delivery systems. Reported cost estimates also are limited to the study sample size for each cancer site, stage at diagnosis, and patient age at diagnosis. However, use of the phase-of-care approach and the KMSA method leverages existing data efficiently and yields cost estimates that are useful for stakeholders to understand the costs of investing in cancer care. ${ }^{34}$ The costs reported in our study do not include out-of-pocket expenses associated with cancer care; future studies that estimate these expenses for patients are warranted.

Lastly, this study is based on medical care that occurred before implementation of the Affordable Care Act (ACA), which was designed, in part, to reduce overall healthcare costs. Therefore, there are a number of ways that the ACA could also affect cancer costs, such as (1) reforming provider and Medicare Advantage plan payments, (2) providing alternative delivery and payment models (eg, Accountable Care Organizations) that move away from fee-for-service toward value-based reimbursement, and (3) increasing individuals' access to cancer prevention services through Medicaid expansion and essential health benefit coverage. ${ }^{49}$ As more data become available, the impact of the ACA on cancer care costs will be an important area for future research.

\section{Conclusions}

The costs of cancer care reported in this study increase understanding of the magnitude of medical care resources, including those specific to cancer (net costs), needed to provide services to individuals diagnosed with the 4 most commonly diagnosed cancers in the United States. The high costs of medical care for patients aged $<65$ years and those diagnosed with lung cancer suggest that it may be important to focus on these population groups to control increasing costs of cancer care, particularly because US trends indicate that nearly half of all new cancer diagnoses occur among those aged $<65$ years and that lung cancer is the second-most commonly diagnosed cancer among US adults. ${ }^{26}$ Further, the high costs of advanced-stage cancers highlight the substantial economic burden to the healthcare system and patients, and the importance of early detection strategies. Overall, medical care cost estimates using different data sources and patient populations are necessary to enhance our knowledge of the role of various healthcare delivery settings in determining the costs of cancer care.

\section{References}

1. Soni A. Top five most costly conditions among adults age 18 and older, 2012: estimates for the U.S. civilian noninstitutionalized population. Statistical Brief \#471. Rockville, MD: Agency for Healthcare Research and Quality; 2015. Available at: http://www.meps.ahrq.gov/mepsweb/ data_files/publications/st471/stat471.pdf.

2. Jagsi R. Debating the oncologist's role in defining the value of cancer care: we have a duty to society. J Clin Oncol 2014;32:4035-4038.

3. Newcomer LN. Innovative payment models and measurement for cancer therapy. J Oncol Pract 2014;10:187-189.

4. Institute of Medicine. Ensuring Patient Access to Affordable Cancer Drugs: Workshop Summary. Washington, DC: The National Academies Press; 2014.

5. Bach PB. Limits on Medicare's ability to control rising spending on cancer drugs. N Engl J Med 2009;360:626-633.

6. Mariotto AB, Yabroff KR, Shao Y, et al. Projections of the cost of cancer care in the United States: 2010-2020. J Natl Cancer Inst 2011;103:117128.

7. Lipscomb J. Estimating the cost of cancer care in the United States: a work very much in progress. J Natl Cancer Inst 2008;100:607-610.

8. Guy GP Jr, Ekwueme DU, Yabroff KR, et al. Economic burden of cancer survivorship among adults in the United States. J Clin Oncol 2013;31:3749-3757.
9. Ekwueme DU, Yabroff KR, Guy GP Jr, et al. Medical costs and productivity losses of cancer survivors-United States, 2008-2011. MMWR Morb Mortal Wkly Rep 2014;63:505-510.

10. Zheng Z, Yabroff KR, Guy GP Jr, et al. Annual medical expenditure and productivity loss among colorectal, female breast, and prostate cancer survivors in the United States. J Natl Cancer Inst 2016;108:djv382.

11. Howard DH, Molinari NA, Thorpe KE. National estimates of medical costs incurred by nonelderly cancer patients. Cancer 2004;100:883-891.

12. Thorpe KE, Howard D. Health insurance and spending among cancer patients. Health Aff (Millwood) 2003:W3-189-198.

13. Yabroff KR, Dowling EC, Guy GP Jr, et al. Financial hardship associated with cancer in the United States: findings from a population-based sample of adult cancer survivors. J Clin Oncol 2016;34:259-267.

14. Brown ML, Riley GF, Schussler N, Etzioni R. Estimating health care costs related to cancer treatment from SEER-Medicare data. Med Care 2002;40(8 Suppl):IV-104-117.

15. Warren JL, Brown ML, Fay MP, et al. Costs of treatment for elderly women with early-stage breast cancer in fee-for-service settings. J Clin Oncol 2002;20:307-316.

16. Yabroff KR, Lamont EB, Mariotto A, et al. Cost of care for elderly cancer patients in the United States. J Natl Cancer Inst 2008;100:630-641.

17. Brown ML, Riley GF, Potosky AL, Etzioni RD. Obtaining long-term disease specific costs of care: application to Medicare enrollees diagnosed with colorectal cancer. Med Care 1999;37:1249-1259. 
Banegas et al

18. Ramsey SD, Mandelson MT, Berry K, et al. Cancer-attributable costs of diagnosis and care for persons with screen-detected versus symptomdetected colorectal cancer. Gastroenterology 2003;125:1645-1650.

19. Etzioni R, Urban N, Baker M. Estimating the costs attributable to a disease with application to ovarian cancer. J Clin Epidemiol 1996;49:95-103.

20. Stokes ME, Ishak J, Proskorovsky I, et al. Lifetime economic burden of prostate cancer. BMC Health Serv Res 2011;11:349.

21. Lang $K$, Lines $L M$, Lee $D W$, et al. Lifetime and treatment-phase costs associated with colorectal cancer: evidence from SEER-Medicare data. Clin Gastroenterol Hepatol 2009;7:198-204.

22. Lang K, Menzin J, Earle CC, et al. The economic cost of squamous cell cancer of the head and neck: findings from linked SEER-Medicare data. Arch Otolaryngol Head Neck Surg 2004;130:1269-1275.

23. Yancik R, Wesley MN, Ries LA, et al. Effect of age and comorbidity in postmenopausal breast cancer patients aged 55 years and older. JAMA 2001;285:885-892.

24. White J, Morrow M, Moughan J, et al. Compliance with breastconservation standards for patients with early-stage breast carcinoma. Cancer 2003;97:893-904.

25. Giordano SH, Hortobagyi GN, Kau SW, et al. Breast cancer treatment guidelines in older women. J Clin Oncol 2005;23:783-791.

26. Howlader N, Noone AM, Krapacho M, et al. SEER Cancer Statistics Review, 1975-2012. Bethesda, MD: National Cancer Institute; 2015.

27. Taplin SH, Barlow W, Urban N, et al. Stage, age, comorbidity, and direct costs of colon, prostate, and breast cancer care. J Natl Cancer Inst 1995;87:417-426.

28. Chubak J, Ziebell R, Greenlee RT, et al. The Cancer Research Network: a platform for epidemiologic and health services research on cancer prevention, care, and outcomes in large, stable populations. Cancer Causes Control 2016;27:1315-1323.

29. National Cancer Institute. Cancer Research Network: Healthcare Delivery Research Program, Division of Cancer Control \& Population Sciences, National Cancer Institute, National Institutes of Health; 2017. Available at: https://crn.cancer.gov/. Accessed March 2, 2018.

30. Hornbrook MC, Fishman PA, Ritzwoller DP, et al. When does an episode of care for cancer begin? Med Care 2013;51:324-329.

31. O'Keeffe-Rosetti MC, Hornbrook MC, Fishman PA, et al. A standardized relative resource cost model for medical care: application to cancer control programs. J Natl Cancer Inst Monogr 2013;2013:106-116.

32. Hornbrook MC, Hart G, Ellis JL, et al. Building a virtual cancer research organization. J Natl Cancer Inst Monogr 2005:12-25.

33. Riley GF, Potosky AL, Klabunde CN, et al. Stage at diagnosis and treatment patterns among older women with breast cancer: an $\mathrm{HMO}$ and fee-for-service comparison. JAMA 1999;281:720-726.

34. Barlow WE. Overview of methods to estimate the medical costs of cancer. Med Care 2009;47(Suppl 1):S33-36.

35. NSEER Program. SEER*Stat Database: Incidence - SEER 9 Regs Research Data, Nov 2016 Sub (1973-2014) <Katrina/Rita Population Adjustment> - Linked To County Attributes - Total U.S., 1969-2015 Counties, National
Cancer Institute, DCCPS, Surveillance Research Program. Based on November 2016 submission. Posted April 2017.

36. Yabroff KR, Warren JL, Banthin J, et al. Comparison of approaches for estimating prevalence costs of care for cancer patients: what is the impact of data source? Med Care 2009;47(Suppl 1):S64-69.

37. Stokes ME, Black L, Benedict A, et al. Long-term medical-care costs related to prostate cancer: estimates from linked SEER-Medicare data. Prostate Cancer Prostatic Dis 2010;13:278-284.

38. Cipriano LE, Romanus D, Earle CC, et al. Lung cancer treatment costs, including patient responsibility, by disease stage and treatment modality, 1992 to 2003. Value Health 2011;14:41-52.

39. Fireman BH, Quesenberry CP, Somkin CP, et al. Cost of care for cancer in a health maintenance organization. Health Care Financ Rev 1997;18:5176.

40. U.S. Preventive Services Task Force. Final Recommendation Statement: Lung Cancer: Screening. Available at: https:// www.uspreventiveservicestaskforce.org/Page/Document/ RecommendationStatementFinal/lung-cancer-screening. Accessed March 2, 2018.

41. U.S. Preventive Services Task Force. Final Update Summary: Colorectal Cancer:Screening. Available at: https://www.uspreventiveservicestaskforce. org/Page/Document/UpdateSummaryFinal/colorectal-cancer-screening2.

42. U.S. Preventive Services Task Force. Final Update Summary: Breast Cancer: Screening. Available at: https://www.uspreventiveservicestaskforce.org/ Page/Document/UpdateSummaryFinal/breast-cancer-screening1.

43. Office of Disease Prevention and Health Promotion. Healthy People 2020. Available at: https://www.healthypeople.gov/2020/. Accessed March 2, 2018.

44. National Cancer Institute: Surveillance, Epidemiology, and End Results Program. Cancer Stat Facts: Cancer of Any Site. Available at: https://seer cancer.gov/statfacts/html/all.html. Accessed March 2, 2018.

45. Yabroff KR, Francisci S, Mariotto A, et al. Advancing comparative studies of patterns of care and economic outcomes in cancer: challenges and opportunities. J Natl Cancer Inst Monogr 2013;2013:1-6.

46. American Society of Clinical Oncology. The state of cancer care in America, 2016: a report by the American Society of Clinical Oncology. J Oncol Pract 2016;12:339-383.

47. Howlader N, Noone AM, Krapcho M, et al, eds. SEER Cancer Statistic Review, 1975-2014, National Cancer Institute. Available at: https:/ seer.cancer.gov/csr/1975_2014/. Based on November 2016 SEER data submission. Posted April 2017.

48. Howlader N, Noone AM, Krapacho M, et al, eds. SEER Cance Statistics Review, 1975-2013, National Cancer Institute. Bethesda, MD National Cancer Institute; 2016. Available at: https://seer.cancer.gov/ csr/1975_2013/.

49. Abrams MK, Nuzum R, Zezza MA, et al. The Affordable Care Act's Payment and Delivery System Reforms: A Progress Report at Five Years. New York, NY: The Commonwealth Fund; 2015. 